Bol. Acad. peru. leng. 62. 2017 (91-109)

\title{
La ética del amor y la ética del deseo en la poesía de César Moro
}

\author{
Ethics of love and ethics \\ of desire in the poetry of Cesar Moro \\ VÍCTOR VICH \\ Pontificia Universidad Católica del Perú
}

Resumen:

¿Qué es el amor para Moro? ¿Qué es el deseo? ¿Qué los provoca? ¿Qué efectos tienen en la subjetividad? Me propongo estudiar las dinámicas del amor y del deseo en la poesía de César Moro a partir de tres tipos de imágenes: como acontecimientos que instalan un proceso de verdad, como fuerzas que suspenden la moral tradicional y como los signos de algo que desborda a la subjetividad y que apunta más allá de toda lógica racional.

\section{Abstract:}

What is love for Moro? What is desire? What causes them? What effects do they have in subjectivity? I intend to study the dynamics of love and desire in the poetry of Cesar Moro using three types of images: as events leading to a process of truth, as forces suspending traditional moral and as signs of something that goes 
beyond to the subjectivity and depart from any rational logic.

Palabras clave: César Moro, poesía peruana, ética, amor, deseo.

Keywords: Cesar Moro, Peruvian poetry, ethics, love, desire.

Recibido: 15/09/2017

Aceptado: 20/10/2017

Yo he pagado mi sed con piedras candentes

El lenguaje es un instrumento que establece un cierto orden en el mundo, pero sabemos bien que ese orden es arbitrario y que, al desordenarse, puede desembocar en la locura. Sus principios intentan ser lógicos, pero no es difícil notar que en su interior habita una profunda irracionalidad. El uso del lenguaje puede llevarnos a lugares completamente disímiles. Por un lado, a un lugar estable donde cada cosa tiene su lugar y cuenta con una identidad permanente, pero también a una dimensión donde todo se desordena y donde el caos y el goce pueden imponer su presencia.

César Moro, ese poeta peruano cuya vida estuvo marcada por innumerables decepciones, pero también por intensos compromisos, asumió la poesía como un territorio «sin garantías», como aquel lugar para simbolizar lo incomunicable, la falta de sentido, el abismo de la existencia, esa «parte maldita» a la que se llega luego de todas las sustracciones y de todos los riesgos posibles. 
En líneas generales, Moro optó por el surrealismo al que entendió como un proyecto de liberación que le permitía hacerse cargo de una identidad descentrada siempre constituida bajo intensos desplazamientos. Moro supo que si hay algo que le hace daño al sujeto es la falsa ilusión de unidad y, por eso mismo, entendió que la tranquilidad no solo era imposible sino quizá indeseable.

¿Qué es el amor para Moro? ¿Qué es el deseo? ¿Qué los provoca? ¿Qué efectos tienen en la subjetividad? En este ensayo, voy a discutir lo que llamaré la «ética del amor» y la «ética del deseo» como dos dinámicas enfrentadas en las cuales, una de ellas, la del amor, se establece como un cierto garante de la satisfacción, y la otra, la del deseo, más bien reconoce la incompletud constitutiva de la condición humana y el vacío como una falta de sentido que nunca podrá llenarse del todo. Como radical experiencia de libertad, el amor aparece aquí como una forma de subjetivación, como el acceso a una dimensión otra de la existencia situada más allá de la moral y de toda utilidad práctica. En esta poesía, el amor se asocia con el deseo (el cual sostiene) y su surgimiento pone en juego una dinámica donde el exceso se hace presente aunque se sepa que nunca pueda llenar la falta. Digámoslo más claramente: si el amor es la promesa de un garante absoluto, el deseo, por el contrario, constata la imposibilidad de cierre y comprueba una insatisfacción que nunca puede saciarse.

Me propongo entonces estudiar las dinámicas del amor y del deseo a partir de tres imágenes que aparecen recurrentemente en esta poesía: como manifestaciones de la incompletud humana (Lacan 1983), como aquellos excesos que apuntan más allá de toda lógica racional y 
de toda moralidad establecida (Bataille 2006) y como acontecimientos que instalan una verdad (Badiou 2011). Comencemos entonces con un primer texto, con la segunda parte del largo poema titulado «El fuego y la poesía» que apareció en La tortuga ecuestre, libro póstumo publicado en 1958:

Amo el amor de ramaje denso

Salvaje al igual de una medusa

El amor-hecatombe

Esfera diurna en que la primavera total

Se columpia derramando sangre

El amor de los anillos de la lluvia

De rocas transparentes

De montañas que vuelan y se esfuman

Y se convierten en minúsculos guijarros

El amor como una puñalada

Como un naufragio

La pérdida total del habla del aliento

El reino de la sombra espesa

Con los ojos salientes y asesinos

La saliva larguísima

La rabia de perderse

El frenético despertar en medio de la noche

Bajo la tempestad que nos desnuda

Y el rayo lejano transformando los árboles

En leños de cabellos que pronuncian tu nombre

Los días y las horas de desnudez eterna.

(Moro 2016: 46)

Notemos que este poema se esfuerza por representar algunos de los efectos del amor en la subjetividad. Aquí la técnica de la enumeración (parcialmente caótica) se utiliza para representar al amor como una fuerza cataclísmica que arrolla al sujeto y que es capaz de mostrarlo 
en toda su fragilidad y desnudez. En estos versos, en efecto, al amor se le figura como algo externo que se impone sobre el sujeto y que, poco a poco, comienza a tomar toda la subjetividad.

De hecho, el amor aparece representado como una hecatombe, como una especie de terremoto que revuelve la identidad personal. Lejos de proporcionar calma y tranquilidad, se trata de una fuerza desestructuradora que logra que las montañas implosionen y se disuelvan en el horizonte. Por eso mismo, se le figura como la Medusa, como una puñalada, como algo extremadamente peligroso. Son muchas las palabras que terminan asociando al amor con impulsos violentos que van contra la cultura: "sangre derramada», "ojos asesinos», pérdidas de todo tipo. El amor es algo que se incrusta en el cuerpo y que abre una brecha en el lenguaje.

Sin embargo, no es el amor una fuerza negativa que pueda hacerle daño a la subjetividad. Se trata, más bien, de una fuerza que desestabiliza las bases a partir de las cuales el sujeto ha sido constituido y que puede abrirlo hacia otra dimensión. En estos versos, el amor y el deseo son fuerzas que perturban lo que se ha sedimentado y que remueven aquello que ha caído en la inercia de la cotidianidad. Cuando dicen que el amor implica «la pérdida total del habla del aliento» se está nombrando, no a la muerte, sino al comienzo de una nueva etapa. El amor aparece entonces como un acontecimiento que muestra la insuficiencia de la cotidianidad y los límites del sentido. Como ruptura y como quiebre suspende algo del tiempo, muestra nuevos horizontes y neutraliza el poder de la moral asentada. 
Para Moro, entonces, el verdadero amor no es un momento de paz sino un agente de cambio, de sustracción, una fuerza que activa el paso de un lugar a otro. De hecho, esta es una poesía que se da perfecta cuenta de que el mundo es inestable, de que el sujeto no tiene una identidad fija y de que, por lo mismo, puede involucrarse con cambios radicales. El amor es aquí «el frenético despertar en medio de la noche [...] bajo una tempestad que nos desnuda» $y$, es posible interpretarlo, se trata de un acontecimiento que trae una verdad inédita, un contacto con algo verdadero de lo que no se puede dudar. De esta manera, su presencia implica entrar en contacto con algo que nos deja desnudos, que sustrae todos los garantes porque fuerza a desprenderse de buena parte de los mandatos de la cultura. «A vista perdida» es otro poema de La tortuga ecuestre en cuyo comienzo debemos detenernos:

No renunciaré jamás al lujo insolente al desenfreno suntuoso

De palos como fasces finísimas colgadas de cuerdas y

De sables

Las paisajes de la saliva inmensos y con pequeños cañones de

Plumas fuentes

El tornasol violento de la saliva

La palabra designando el objeto propuesto por su contrario

El árbol como una lamparilla mínima

La pérdida de las facultades y la adquisición de la demencia

El lenguaje afásico y sus perspectivas embriagadoras

La logocloina el tic la rabia el bostezo interminable

La estereotipia el pensamiento prolijo

El estupor 
[...]

No renunciaré jamás al lujo primordial de tus caídas vertiginosas

Oh locura de diamante.

(Moro 2016: 25)

Volvamos a notar que, en estos versos, la voz poética es portadora de una convicción y que no tiene miedo de hacerla pública. Ha descubierto una verdad y está dispuesta a defenderla a como dé lugar. Gracias a ella, puede reconocer que la realidad es mucho más abierta a como suele presentarse. Nuevamente, este es un poema que se enfrenta a la moral tradicional y que construye una voz que ha optado por dar un testimonio que es, al mismo tiempo, una fe y un combate. «No renunciaré» afirman un par de versos y lo hacen de una forma, ya radical, que no admite matices de ningún tipo.

Podemos decir entonces que lo que aquí se defiende es el exceso y la trasgresión. De hecho, los versos figuran al amor y al deseo como aquellas fuerzas que son capaces de sacarnos de los límites impuestos. En estos poemas, las imágenes son siempre alucinadas y apuntan al elogio de la locura que es también el elogio del amor. La locura es figurada aquí como un lugar de exceso, como la llave para descubrir otra dimensión de la realidad o, mejor dicho, para comenzar a vivir de otra manera.

Detengámonos aquí: ¿cuál es la «verdad» que se ha descubierto? La respuesta no puede ser otra que la «verdad del deseo». Por eso mismo, los versos se enfrentan a toda normativa que intente reprimirlos y 
la voz poética intenta liberarse de todos los mandatos impuestos por el lenguaje y la cultura. Desde ahí, la poesía se convierte entonces en un lugar donde la arbitrariedad del signo se hace más visible y donde ya no es necesario aparentar coherencia. Veamos algunos versos del poema titulado «Un camino de tierra en medio de la tierra» también del mismo libro:

\section{Vivir bajo las algas}

El sueño en la tormenta sirenas como relámpagos el alba Incierta un camino de tierra en medio de la tierra y nubes De tierra y tu frente se levanta, como un castillo de nieve Y apaga el alba y el día se enciende y vuelve la noche y fasces de tu pelo se interponen y azotan el rostro helado de la noche

Para sembrar el mar de luces moribundas

Y que las plantas carnívoras no falten de alimento

Y crezcan ojos en las playas

$\mathrm{Y}$ las selvas despeinadas giman como gaviotas

(Moro 2016: 24)

Nuevamente, el poema es muy claro en subrayar la firme opción de ingresar a un territorio desconocido donde el lenguaje pierde lógica y donde es necesario afrontar su propia arbitrariedad. Nuevamente, la intensidad de estas imágenes pueden interpretarse como un punto de fuga de los sentidos existentes. Para Vasi, este es un poema en el que la imaginería naturalista incrementa, simultáneamente, la presencia y la ausencia del deseo erótico (2016: 42). Se trata, en efecto, de un tipo de escritura que apunta a confrontarnos con el exceso mismo entendido tanto en sus dinámicas constructivas como destructivas. Aquí, el 
exceso es figurado como libertad, pero también como trasgresión y locura.

De hecho, el poema tiene que ver con el goce, con la pulsión de muerte, con algo placentero, pero a la vez cruel y doloroso. La aparición del amado es central en esta dinámica, pues su presencia parece ejercer un poder inusitado sobre la realidad existente. Se trata de alguien que renueva la realidad y enardece todo lo que hay en el mundo. Desde ahí, el amor es otra vez descrito en términos apocalípticos: «sueño en la tormenta», «sirenas como relámpagos», "alba incierta», dicen los versos. Nuevamente, nos encontramos muy lejos de la representación del amor como un sentimiento tranquilo y estable. Más bien, se trata de un torrente que desestabiliza (o sustrae) todos los sentidos existentes e instala una verdad que invoca a refundar el mundo, horadándolo, desde muchas perspectivas. Notemos esta misma dinámica en algunos versos del poema «Arreglo de cuentas» del libro escrito en francés titulado Le château de grisou:

Debemos el iris del ojo el rocío la embriaguez

De una noche en que querías derribarme llevaba yo una Negra bandera

La noche en que todas las llamas hablaban a boca cerrada

Ojos desviados y retornados en la bahía

La noche en que todo hablaba de un encantador deseo

De muerte

En que las lágrimas habiendo dicho todo querían llevarme a

Otro sitio

Hacia una soberbia tumba de polvo de mármol

Un tumulto de hipnosis progresiva 
La violencia prometida el atractivo irregular Siempre el fuego del pensamiento la idea fija Si yo quisiera vivir no sería en esta isla

(Moro 2016: 123) ${ }^{1}$

Podríamos decir que el amor es aquí un lugar donde el sujeto puede observar su derrota, donde se hace visible su falta de control, donde una voluntad otra emerge como superior a la de uno mismo. El último verso ( «Si yo quisiera vivir no sería en esta isla») muestra bien cómo la voz poética pone en cuestión el régimen de verdad existente, vale decir, el horizonte normativo de sentido que ha estructurado la vida; ese marco que gobierna la producción de la subjetividad, del deseo y de los sentidos últimos. Sin duda, esta es una voz rebelde que ya no se reconoce en la realidad existente y que lucha contra esas normas. Si el poema es una invocación a la muerte, ella no es figurada como el final de la vida sino, más bien, como el acceso a otra vida. Es entonces porque desencadena un final, que el amor puede inaugurar algo de lo nuevo. Se trata, por eso mismo, de algo siempre incisivo anclado en el iris del ojo, en el rocío, en aquellas excepciones que se abren sin complejos a lo infinito del deseo.

1 La traducción es de Ricardo Silva-Santisteban. El original en francés dice lo siguiente: «Nous devons l'iris de l'oeil la rosée l'ivresse / D'une nuit où tu voulais m'abattre je portais un drapeau noir / La nuit où toutes les flammes parlaient bouche close / Yeux détournés et rentrés dans la baie / La nuit où tout parlait d'un enchanteur désir de mort / Où les larmes avant tout dit voulaient me porter ailleurs / Vers un superbe tombeau de poussière de marbre / Un tumulte d'hypnose progressive / La violence promise l'attirance irrégulière / Toujours le feu de la pensée l'idée fixe / Si je voulais vivre ce ne serait pas sur cette île». 
Afirmemos, sobre todo, que la poesía de Moro muestra una voz que ha dejado sentir culpa y que insiste en reconciliarse con el exceso de su deseo. Los poemas aceptan la falta de coherencia y, sobre todo, la convierten en un bastión crítico. Desde ahí, sin embargo, podemos hacernos la siguiente pregunta: ¿le hace bien el amor al sujeto? La respuesta de Moro es que sí. Esta poesía afirma que sin amor no hay empalme con lo Real (lacaniano), acceso a lo sagrado, contacto con la verdad. En ella, el amor es lo que hace que el sujeto pueda refundarse subjetivamente porque sustrae todos los sentidos de la realidad y, por lo mismo, logra articularse con algo de lo Real del sujeto y del mundo. Un poema titulado «La leve pisada del demonio nocturno» de La tortura ecuestre termina por figurarlo así:

En el gran contacto del olvido A ciencia cierta muerto

Tratando de robarte a la realidad

$\mathrm{Al}$ ensordecedor rumor de lo real

Levanto una estatua de fango purísimo

De barro de mi sangre

De sombra lúcida de hambre intacto

De jadear interminable

$Y$ te levantas como un astro desconocido

Con tu cabellera de centellas negras

Con tu cuerpo rabioso e indomable

Con tu aliento de piedra húmeda

Con tu cabeza de cristal

Con tus orejas de adormidera

Con tus labios de fanal

Con tu lengua de helecho

Con tu saliva de fluido magnético

Con tus narices de ritmo

Con tus pies de lengua de fuego 
Con tus piernas de millares de lágrimas petrificadas

Con tus ojos de asalto nocturno

Con tus dientes de tigre

Con tus venas de arco de violín

Con tus dedos de orquesta

Con tus uñas para abrir las entrañas del mundo

Y vaticinar la pérdida del mundo

En las entrañas del alba

Con tus axilas de bosque tibio

Bajo la lluvia de tu sangre

Con tus labios elásticos de planta carnívora

Con tu sombra que intercepta el ruido

Demonio nocturno

Así te levantas para siempre

Pisoteando el mundo que te ignora

$Y$ que ama sin saber tu nombre

Y que gime tras el olor de tu paso

De fuego de azufre de aire de tempestad

De catástrofe intangible y que merma cada día

Esa porción en que se esconden los designios nefastos y la sospecha que tuerce la boca del tigre que en las mañanas escupe para hacer el día

(Moro 2016: 40-41)

Si el amor es una fuerza que permite alcanzar lo sagrado a través de lo erótico, podemos notar cómo, en este poema, amar es sentirse profundamente avasallado pero, más aún, amar implica avasallar al mundo. Nuevamente, el poema opta por una estética de la enumeración caótica que juega en paralelo con un yo que se pierde y casi desaparece a efectos de la intensidad que el otro posee. Este poema convierte al sujeto amado en alguien absoluto y toda su retórica trata de nombrar la intensidad de lo que ese otro representa para el sujeto que enuncia. 
Dicho de otra manera: esta es una voz en la que el sujeto solo puede constituirse como tal a través del intento por entablar una relación con el otro. Sin embargo, casi podría decirse que toda esta escritura surge para tematizar la perturbación que surge al no poder encontrar una representación adecuada. «Cuando te veo simplemente te veo, pero solo cuando te nombro puedo identificar el abismo que hay en ti detrás de lo que veo» ha sostenido Žižek a fin de marcar cómo el amor abre una brecha entre lo que el sujeto desea y el límite de lo que puede simbolizar con sus palabras (2005: 95).

En ese sentido, Marcos Mondoñedo (2017) ha sostenido que en la poesía de Moro «el cosmos se ha destruido; en su lugar quedan partes del ser humano como causas del deseo", y que esas partes no son semblantes imaginarios ni realidades simbólicas, sino objetos cargados de vacío y de antagonismos que articulan algo de lo Real. En efecto, aquí los versos insisten en esa búsqueda de nombres y acciones parciales como sustitutas de la totalidad. El poeta descubre que cada descripción es insuficiente, pero sabe también que cada parte captura algo trascendente y que inviste como una encarnación del todo absoluto. Al fragmentarse, el cuerpo se vuelve un lugar cargado de mayor erotismo. Esta es una poesía cuyas figuraciones del amor se inscriben al interior de una estética materialista donde el amor emerge como un acontecimiento que hace posible que emerja una verdad anclada en el cuerpo.

En suma, para esta poesía el amor erótico es gastar, perderse, salirse del mundo racional. Es, sobre todo, un acto excesivo y desequilibrante. Bataille (2006) subrayó 
que fuerzas así siempre están más allá de toda utilidad y que solo puede accederse a ellas a través del «gasto improductivo». Es en la experiencia del amor (que el erotismo activa) que el yo se pierde a sí mismo para reencontrarse consigo mismo de otra manera y solo desde ahí puede vislumbrarse (y anunciarse) «la otra margen»: un lugar sin garantías, pero cargado de necesidad de lazo. De hecho, es en la experiencia del amor donde se experimenta algo de uno mismo que se desconocía hasta ese momento y que parece cercano al sacrificio.

Insistamos: el poema intenta subrayar que el encuentro con el otro genera una profunda transformación del yo a partir de la cual ya no hay retorno posible. La subjetividad debe dejarse llevar por ese «ensordecedor rumor de lo real» y debe hacer suya la opción de abrir las entrañas hacia «esa saliva de fluido magnético» que conduce a otro lugar. En efecto, en esta poesía, el amor consiste en el ingreso a un lugar del que no se sabe casi nada, pero del que sí se ha experimentado algo. Este contacto requiere «ojos de asalto nocturno» a fin de enfrentar toda crisis del sentido. Por eso mismo, el amor siempre implica un pecado o algún tipo de condena. Los versos representan un proceso de desubjetivación que coloca a la voz poética como un vasallo del otro, pero también (o sobre todo) como un dramático vasallo de sí mismo².

Hemos llegado a la pregunta final: ¿es esta una poesía del amor o del deseo? En los versos, no está muy

2 Debo esta frase - y muchas otras ideas - a permanentes conversaciones con Juan Carlos Ubilluz. 
clara la diferencia, pues si por un lado las imágenes muestran una fantasía que nunca se sacia, por otro, es también claro que la entrega hacia el otro resulta ser de tal magnitud, de tal fidelidad, que afirma la presencia de un garante en el que se proyecta todo un nuevo sentido. Expliquémonos mejor. En la poesía de Moro, la "ética del amor» consiste en elevar a alguien a una condición de absoluto, vale decir, de investirlo como aquel ser trascendente que podría ser capaz de salvar al sujeto de los sentidos tradicionales de la cultura. Si bien lo trascendente nunca es alcanzable en su totalidad, se apuesta a los objetos parciales como instrumentos capaces de activar una verdad. En ese sentido, se trata de una poesía que construye una «ética del amor» como una terca decisión, con un acto de fidelidad hacia la verdad y el deseo.

Sin embargo, también podemos decir que esta es una poesía de la «ética del deseo» debido a que la voz poética parece reconocer el carácter siempre imposible de su satisfacción. En efecto, Yolanda Westphalen ha afirmado que, para Moro, el amor es siempre una carencia $y$, de hecho, es de notar que esta es una poesía que vive en el deseo y que, desde ahí, asume dignamente su condición inconclusa y su carácter siempre pendiente (2001: 67). «Amo la rabia de perderte» es un famoso verso donde se marca la necesidad de hacer fértil la propia insatisfacción. El deseo es entonces el intenso ardor para insistir en lo que no se tiene, para no desmayar ante la pérdida y ante el fracaso.

De todas formas, tanto el amor como el deseo son, en última instancia, fuerzas que activan la capacidad de poder simbolizar, a través de las palabras, nuevas 
posibilidades humanas. Para acceder a lo sagrado, el sujeto no solo debe perderse a sí mismo sino además debe perderse en el lenguaje. Si la creación literaria adquiere un carácter compulsivo, lo hace por su opción de adentrarse en el vértigo mismo de la existencia, en un lugar de libertad extrema, en la opción por llegar al «loco amor» del que hablaban los surrealistas. Moro entendió la poesía como una maldición, pero también como un don, como una acción rebelde, como una especie de ofrenda ritual para capturar el exceso, abolir el tiempo y cuestionar la realidad tal como la conocemos (Westphalen 2001: 96). Con acierto, Lauer ha sostenido que lo que Moro introduce en la poesía peruana es «una relación particular con la rebeldía como radical manifestación de la libertad en lucha con el orden establecido» (2012: 68). Enfrentado a la moral tradicional, esta poesía descubrió al amor como un ardoroso camino por el «ramaje denso»y por la «sombra espesa».

La extrema intensidad poética de la obra de César Moro surge de la tensión entre la «ética del amor» y la "ética del deseo», vale decir, de haber constatado un cruel desbalance entre la falta constitutiva de la existencia humana, la legítima inclinación hacia el goce (en el exceso del cuerpo y de las palabras) y el testimonio de haber entrado en contacto con una verdad y un absoluto. El amor trae algo de plenitud, es cierto, pero también de ausencia y soledad. En esta poesía, el sujeto siempre quiere resubjetivizarse al haber entrado en contacto con una verdad pero, al mismo tiempo, reconoce que existe algo quebrado que lo desestructura sin piedad. En sus poemas, en sus cartas y en su vida, Moro notó que la intensidad del amor se debe a la búsqueda 
del otro, a la centralidad del amado, pero también se dio cuenta de que el amado suele desaparecer muy pronto y que este hecho deja siempre un vacío incomprensible en el corazón mismo de la subjetividad. 


\section{Bibliografía}

BADIOU, Alain. Elogio del amor. Madrid, La esfera de los libros, 2011.

BATAILLE, Georges. El erotismo. Barcelona, Tusquets, 2006.

FERRARI, Américo. La soledad sonora. Voces poéticas del Perú en Hispanoamérica. Lima, Pontificia Universidad Católica del Perú, 2003.

LACAN, Jacques. El yo en la teoría de Freud y en la técnica psicoanalítica. 1954-1955. Buenos Aires, Paidós, 1983.

LAUER, Mirko. «Razón y pasión en Moro», en Vanguardistas: una miscelánea en torno a los años 20 peruanos. Lima, Pontificia Universidad Católica del Perú, 2012, págs. 63-73.

MONDOÑEDO, Marcos. «Desde otro cosmogónico hacia el otro real: análisis de la enunciación en "Adresse aux trois regnes", de César Moro», en MONDOÑEDO, Marcos, Martín VARGAS Canchanya y Karen CALLE. Lo que no cesa de no escribirse. La interpretación de lo real y algunos ejemplos de su aplicación en la lírica peruana. Lima, Dedo Crítico Editores, 2014.

. "Traite des etoiles” de César Moro

o el gran desorden de lo real», en Intervenciones y trazos. Año 3, No 4, agosto, 2017.

MORO, César. Obra poética completa. Tomo II. Lima, Sur Librería Anticuaria y Academia Peruana de la Lengua, 2016.

VASI, Fiorella. Las figuraciones del amor en Moro: el exceso y la falta como representaciones de verdad. Tesis de licenciatura en Literatura Hispánica. Lima, Pontificia Universidad Católica del Perú, 2016. 
WESTPHALEN, Yolanda. César Moro. La poética del ritual y la escritura mítica de la modernidad. Lima, Universidad Nacional Mayor de San Marcos, 2001.

ŽIŽEK, Slavoj. El títere y el enano. El núcleo perverso del cristianismo. Buenos Aires, Paidós, 2005. 